\title{
EXPERIMENTAL STUDY OF OPERATIONAL PROPERTIES OF TWO-MACHINE DRILLING AGGREGATE
}

\author{
Volodymyr BULGAKOV**, Pavol FINDURA², Vladimír KROČKO², \\ Ladislav NOZDROVICKÝ ${ }^{2}$, Maroš KORENKO², Volodymyr KUVACHOV ${ }^{3}$ \\ ${ }^{1}$ National University of Life and Environmental Sciences of Ukraine, Ukraine \\ ${ }^{2}$ Slovak University of Agriculture in Nitra, Slovak Republic \\ ${ }^{3}$ Tavria State Agrotechnological University, Ukraine
}

\begin{abstract}
The purpose of this study is to improve the technical and economic performance of the enhanced two-machine seeder based on the wheel-type tractor of traction class 1.4. Experimental research is based on the general provisions of the standard methodology for operational and technological evaluation of the operation of machine-tractor units in the field. Processing of results from experimental study was carried out by means of developed programs on a PC. Results obtained from field experiments testing the aggregate consisting of two-machine seeder of traction class 1.4, two SZ-3.6 seeders and a semi-mounted coupler indicate its high operational and technological efficiency in comparison to both single-machine and similar two-machine units as part of a conventional trailer hitch. Although it shows an increase in specific time losses at headland of up to 5\%, due to the wider working width, utilization of a new two-machine unit on the basis of a semi-mounted coupling in comparison with a single-machine unit allows increasing the productivity of the work by 1.96 and reduction of fuel consumption by $20 \%$. In order to ensure that twomachine unit will perform turning on headland in the optimal mode, it is necessary to equip it with a special automatic device that would change the speed of movement in compliance with the angular speed of tractor's steering wheels according to the developed algorithm.
\end{abstract}

Keywords: tractor-machine aggregate; operational properties; experimental research; efficiency

Research in the area of agricultural engineering can be considered as a very complicated field with the very high and very complex requirements to the management and organization of the individual research steps and operations. According to Adler et al. (1976) and Belij et al. (1989), in connection with the study of machine functions in field conditions, there is a need to use the planning of experiment to determine the optimal conditions for research. Such an approach was used by Bulgakov et al. (2008) in order to study the effectiveness of the aggregation of ploughs with tractors for ploughing in different soil conditions. The quality of the seeding process depends on many factors; therefore, research studies are focused on various scopes. Turan et al. (2014) have oriented their research on studying of sowing quality indicators for a seed drill with overpressure. Turan et al. (2015) aimed their investigation at functions of a seeder with different seeding apparatuses in maize sowing and its impacts on seeding quality. Kuźniar et al. (2016) studied physical and chemical properties of soybean seeds in order to determine their susceptibility to mechanical damage in relation to seeding process. Turan et al. (2017) have developed soybean sowing model. Krjuchev et al. (2009) took a very specific approach to improving the efficiency of tractors (traction class 1.4) and developed a new twomachine unit based on a semi-mounted coupling for sowing of cereals. A widespread trailed version of such a machine is characteristic with a significant length of the seed machinetractor unit. As a result, this leads to a significant (more than $38 \%$ ) increase in time losses during turning on headlands. According to Macák et al. (2011), the accuracy of motion of a seeder is very important factor and utilization of satellite navigation in field machinery during seeding belongs to the most important field practices. Within studies provided by the aforementioned authors, the length of seeding machine was confronted with the accuracy of navigation of individual passes, especially during turning on headlands. According to Cviklovič et al. (2016), there are used different approaches to obtain high accuracy of motion of the mobile machine when working in field conditions and as an example there is mentioned even the navigation algorithm using fuzzy control method.

Field experimental research is based on verification of a working hypothesis that utilization of a semi-mounted coupling in a two-machine seeding machine could reduce its kinematic length and increase the technical and economic performance. Study results regarding justification of the design parameters and operating modes of new high-performance seeders are presented in papers published by Krjuchev et al. (2009) and Nadykto et al. (2012). However, it is possible to evaluate the operational 
and technological efficiency of this unit only by assessing its actual operational properties, characterizing its ability to perform technological process within the agro-technical period with optimal productivity and required quality, as well as with minimal time losses during working shift. Based on the research obtained by Krjuchev et al. (2013), there are very high perspectives of utilization of combined machinetractor aggregates and this fact creates new challenges for research.

The purpose of this study is to improve the technical and economic performance of enhanced two-machine seeder based on a wheeled tractor of traction class 1.4 by justifying recommendations for its effective use based on the experimental determination of operating properties.

\section{Material and methods}

The two-machine seeding aggregate, which we have enhanced, was designed for sowing grain crops and application of mineral fertilizers. It consisted of a tractor of traction class 1.4 (MTZ-80), a newly developed semimounted hitch SS-7.2, and two grain drills SZ-3.6. The scheme of this aggregate is shown in Fig. 1.

The assembly of this enhanced aggregate was possible thanks to the twin-machine semi-mounted hitch SS-7.2 that is shown in Fig. 2.

Special design of semi-mounted hitch SS-7.2 solved the main problem in the assembly of pulling machines, such as the SZ-3.6 grain drill, arising from external arrangement of their support-drive wheels. It was precisely because of this arrangement of support wheels why it was impossible to have a line connection of each seeder to the coupling hitch when turning. Only possible solution to this issue was echelon attachment of seeding machines with help of a semi-mounted coupling hitch that prevented their collisions during unit's turning.

The front width of the SS-7.2 hitch is $7.2 \mathrm{~m}$; the extension of coupling [4] is $2.5 \mathrm{~m}$; its maximum length should not

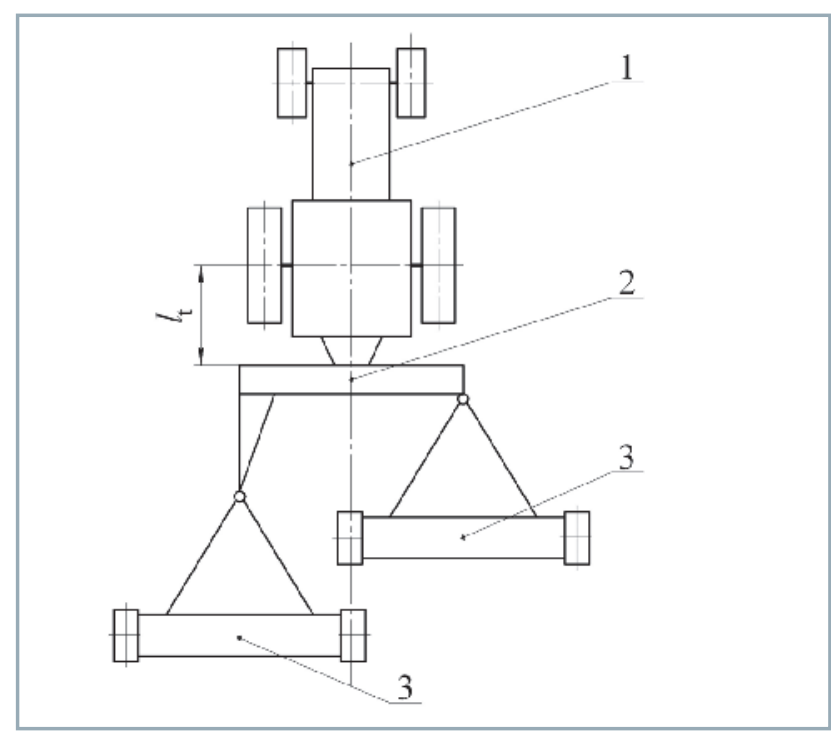

Fig. 1 Scheme of enhanced two-machine seeding aggregate 1 - tractor of traction class 1.4 as a base of aggregate; 2 - new semi-mounted hitch SS-7.2; 3 - grain drills SZ-3.6

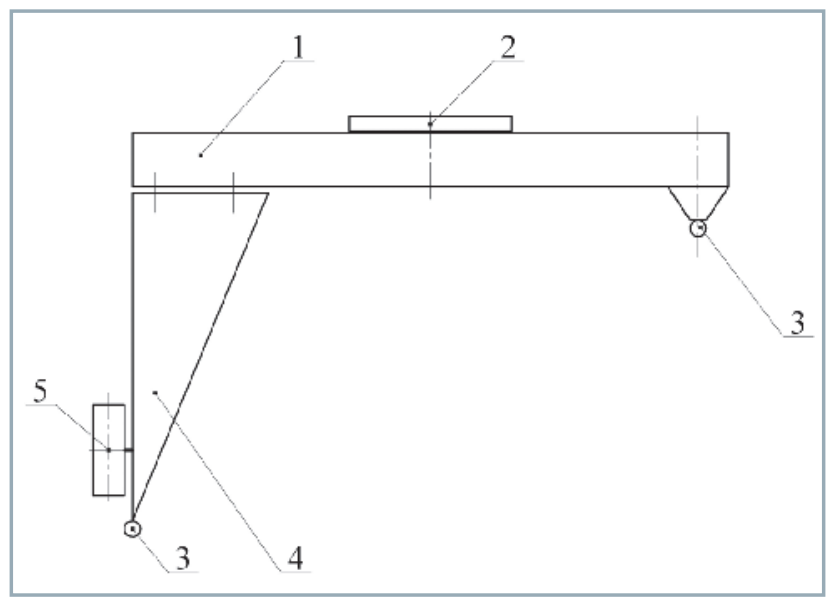

Fig. 2 Scheme of the twin-machine semi-mounted hitch SS-7.2 1 - frame; 2 - lock of the automatic coupler; 3 - trailing link; 4 - extension cable; 5 - support wheel

exceed $3.0 \mathrm{~m}$. The hitch extension [4] is attached to the hitch frame [1], allowing its relative rotation in the longitudinalvertical plane. Free extension end [4] rests on the support vane [5] of the weathervane type. The right grain drill of the machine and tractor unit is connected to a tractor unit by means of trailing link [3] directly to the hitch frame [1] (Fig. 1). The hitch frame [1] hangs from the lock [2] on the rear linkage of the mounting tractor, which is fixed in the working position in a manner that the tow hitch extension [4] is parallel to the plane of the field.

Technological tests and experimental investigation of the enhanced machine consisting of the tractor of traction class 1.4, semi-mounted hitch SS-7.2 and two SZ-3.6 grain drills were performed during applying the ammonium nitrate to soil in order to support the winter wheat germination. The enhanced unit for carrying out this study is shown in Fig. 3.

The conditions and operating mode of the enhanced unit during experimental studies were as follows:

- soil moisture in the layer $0-15 \mathrm{~cm}: 17.5 \%$;

- soil bulk density in the layer 0-15 cm: $1.23 \mathrm{~g} \cdot \mathrm{cm}^{-3}$;

- length of field: $885 \mathrm{~m}$;

- way of movement on headland: loop shuttle;

- average forward speed when turning on headland: $1.9 \mathrm{~m} \cdot \mathrm{s}^{-1}$.

For comparison, during the experimental research, tested two-machine unit worked on headland together with a similar single-machine seeding unit consisting of MTZ-80 tractor and SZ-3.6 seeder.

Before carrying out the experimental studies, the field was divided into sections in order to organize the operation of the compared machine-tractor units. With the given length of $L_{g}$ ridge, width $C$ of enhanced aggregate was determined from the following consideration. A priori assumed were forward speed $v$, working width $B_{w}$, the duration of change $t_{w}$, and the coefficient $\tau$ of its use, and that the target section of the field will be completely processed.

In order to prevent a significant overlapping of working passages of observed machine-tractor unit during fertilizer application, the utilized tractor was equipped with a GPS navigation system CenterLine 220 throughout the experiments (Fig. 4). 


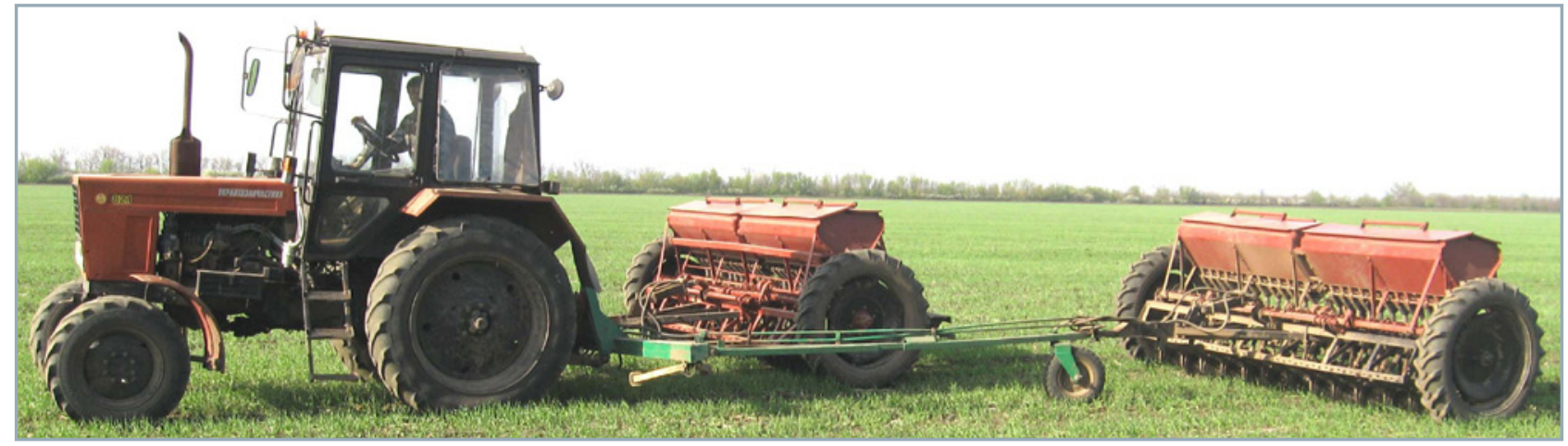

Fig. 3 Experimental two-machine aggregate utilized for application of fertilizers in order to support the winter wheat germination

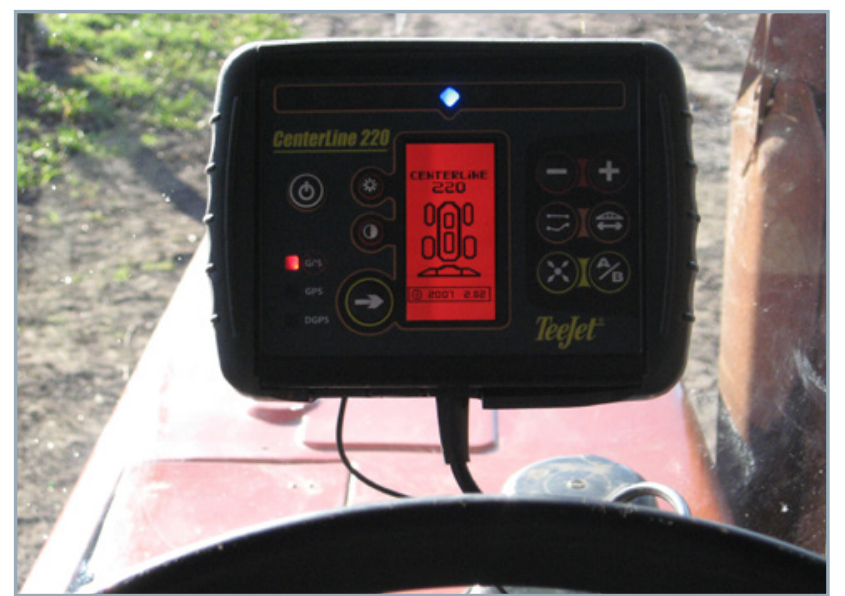

Fig. 4 Interior of the utilized tractor equipped with a GPSnavigator

For calculating the value of $C$, possible thanks to the GPSnavigation, the working width of the aggregate is assumed to be equal to the constructive $B_{w}=7.2 \mathrm{~m}$, the value of which was calculated from the following Eq. (1):

$$
C=\frac{B_{w} \cdot v \cdot t_{w} \cdot \tau}{L_{g}}
$$

It was assumed that the working speed of the aggregate would be $v=2.5 \mathrm{~m} \cdot \mathrm{s}^{-1}$. In addition, it was assumed that $t_{w}=7 \mathrm{~h}$ and $\tau=0.8$ for the organization of the technological process.

According to Eq. (1), the result was $C=410 \mathrm{~m}$. The assessed aggregate was thus utilized in headland sections of $410 \times 885 \mathrm{~m}$ during the topdressing of winter wheat with ammonium nitrate.

\section{Results and discussion}

The PC analysis of the obtained experimental results related to the operation of the experimental two-machine seeding unit showed the following results. In comparison with the

Table 1 Operational and technological performance of the studied sowing machines and tractor aggregates

\begin{tabular}{|c|c|c|c|}
\hline \multirow[t]{2}{*}{ No. } & \multirow{2}{*}{ Indicator } & \multicolumn{2}{|c|}{ Value for the variant of aggregate } \\
\hline & & two machines & one machine \\
\hline \multirow{4}{*}{1} & $\begin{array}{l}\text { Conditions and working regime: } \\
\text { - length of the field }(\mathrm{m})\end{array}$ & \multicolumn{2}{|c|}{885} \\
\hline & - machine forward speed $\left(\mathrm{km} \cdot \mathrm{h}^{-1}\right)$ & 8.8 & 9.0 \\
\hline & - machine working width (m) & 7.2 & 3.6 \\
\hline & - size of the treated area (ha) & 100 & 56 \\
\hline \multirow{3}{*}{2} & $\begin{array}{l}\text { Productivity per } 1 \text { hour: } \\
\text { - of the basic working time (ha) }\end{array}$ & 6.3 & 3.2 \\
\hline & - of the working shift (ha) & 4.9 & 2.5 \\
\hline & - of the operational working time (ha) & 4.8 & 2.4 \\
\hline 3 & Specific fuel consumption $\left(\mathrm{kg} \cdot \mathrm{ha}^{-1}\right)$ & 3.05 & 3.80 \\
\hline \multirow{5}{*}{4} & Operational and technological indicators: & & \\
\hline & - coefficient of utilization of shift time & 0.78 & 0.79 \\
\hline & - coefficient of utilization of operational time & 0.76 & 0.75 \\
\hline & - coefficient of technological working process reliability & 1.0 & 1.0 \\
\hline & - average time of one turning at headland (s) & 44 & 38 \\
\hline
\end{tabular}


analogous single-machine unit, the movement speed of the studied unit was lower by only $2.2 \%$ (Table 1). At the same time, thanks to doubled working width, the performance of the experimental unit was 1.96 times higher. As shown by the results of field experimental studies, the operational performance of unit's work turned out to be 2 times greater.

The results of experimental studies obtained by PC processing showed that the new aggregate unit is more economical (Table 1). The utilization of a new hinged coupling allowed reduction of the specific fuel consumption of the new unit by $0.75 \mathrm{~kg} \cdot \mathrm{ha}^{-1}$, amounting to a saving of $20 \%$.

On the basis of the processed results from field operational and technological experimental studies, it was established that the speed of the assessed unit was at the level $v=1.90 \mathrm{~m} \cdot \mathrm{s}^{-1}$, and the angular velocity of the steering wheels of this aggregate was $\omega=0.16 \mathrm{~s}^{-1}$. As a result, the indicator of the turn mode was $K_{t}=11.9 \mathrm{~m} \cdot \mathrm{rad}^{-1}$, which is larger only by $4.4 \%$ than the optimal value of $11.4 \mathrm{~m} \cdot \mathrm{rad}^{-1}$ (Masalabov, 2012).

The results of field experimental studies have shown that the average time of turning of experimental unit on the headland was higher in comparison with the singlemachine unit by $15.8 \%$.

Specific time $\tau_{21}$ spent on turning of the aggregate on headland, according to the procedure specified by the standard GOST 24055-884 (1988), was determined by means of Eq. (2):

$$
\tau_{21}=\frac{10 T_{21} W_{0}}{L_{g} B_{w}}
$$

where:

$W_{0} \quad$ - working performance of the aggregate during 1 hour of basic working time, ha. $\mathrm{h}^{-1}$

$\tau_{21} \quad$ - duration of turning of the aggregate on headland, $\mathrm{h}$

$$
t_{21}=\frac{\sum_{k=1}^{n} L_{t}}{v}
$$

$\sum_{k=1}^{\text {where: }} L_{t}-$ total length of the aggregate track on headland, $m$

$v \quad$ - average forward speed of the aggregate on headland, $\mathrm{m} \cdot \mathrm{s}^{-1}$

According to the data published by lofinov et al. (1985), the total length of the track of the machine-tractor unit during the turns on headland can be obtained from the following relationship:

$$
\sum_{k=1}^{n} L_{t}=(n-1) \cdot\left(6 R_{c}+2 L\right)
$$

where:

$$
\begin{aligned}
n \quad- & \text { number of working tracks of the aggregate } \\
(n-1)- & \text { number of loop headland turns done by the } \\
& \text { aggregate } \\
R_{c} \quad- & \text { conditional radius of turning on headland, } \mathrm{m} \\
L \quad- & \text { tractor base, } \mathrm{m}
\end{aligned}
$$

In general, the value of $\mathrm{n}$ can be determined from the following expression:

$$
n=\frac{C}{B_{w}}
$$

Taking into account this fact, the experimental twomachine aggregate during the application of mineral fertilizers to the designated area of the field will perform $n=56$ headland turnings with a conventional radius $R_{c}$ equal to:

$$
R_{c}=\sqrt{\frac{K_{t} \cdot L}{\pi}}+\frac{K_{t} \cdot L}{\sqrt{\frac{K_{t} \cdot L}{\pi}}}
$$

According to Eq. (6), we have obtained the conditional turning radius $R_{c}=12.4 \mathrm{~m}$. According to Eq. (4), the total track length of the aggregate unit movement with turning on headland will be equal to:

$$
\sum_{k=1}^{n} L_{t}=4,432 m
$$

Since the movement speed of the aggregate during the headland turning was $v=1.9 \mathrm{~m} \cdot \mathrm{s}^{-1}$, the total time it spent on turning was $\tau_{21}=0.65 \mathrm{~h}$ according to Eq. (3).

On the basis of results from chronometry observations, the rate of the parameter $\tau_{21}$ during one working shift was $0.65 \mathrm{~h}$ for the experimental two-machine aggregate, and $0.60 \mathrm{~h}$ for the basic one-machine aggregate.

In regards to the value of $\tau_{21}$, according to Eq. (2), we get:

$-\tau_{21}=6.0$ for the basic one-machine aggregate;

$-\tau_{21}=6.3$ for the experimental two-machine aggregate.

As it can be seen, the difference in specific time spent on headland turning $\tau_{21}$ between the new seeding machine and tractor unit and the basic one is, though increased, insignificant, since the increment is only $5 \%$.

When mineral fertilizers were applied by an experienced operator, there were no collisions of its seeders during turning at headland. There were no cases of contact between the right trailed seeding machine and the coupling frame when the left-side turn was performed by the sowing machine and tractor unit. In general, the technological process of working and turning on headlands during the field experiments was reliable, as evidenced by the maximum value of the corresponding coefficient equal to 1 (Table 1).

In practice, there were experiments to use a tractor of the traction class 1.4 and two SZ-3.6 seeders with a conventional trailer coupler. However, the length of the turning of such an aggregate was already $9.35 \mathrm{~m}$. This is $57 \%$ more than the observed machine and tractor aggregate on the basis of a new semi-mounted coupling. In addition to this, when it performed, for example, loop turns, the $K_{t}$ mode indicator increased to $24.8 \mathrm{~m} \cdot \mathrm{rad}^{-1}$. Because of this, the value of the conditional radius of rotation $R_{c}$ is $17.9 \mathrm{~m}$ for it.

As a result of field experimental research, it is established that the movement of the enhanced aggregate on the headland in the optimum mode is achieved at a forward 


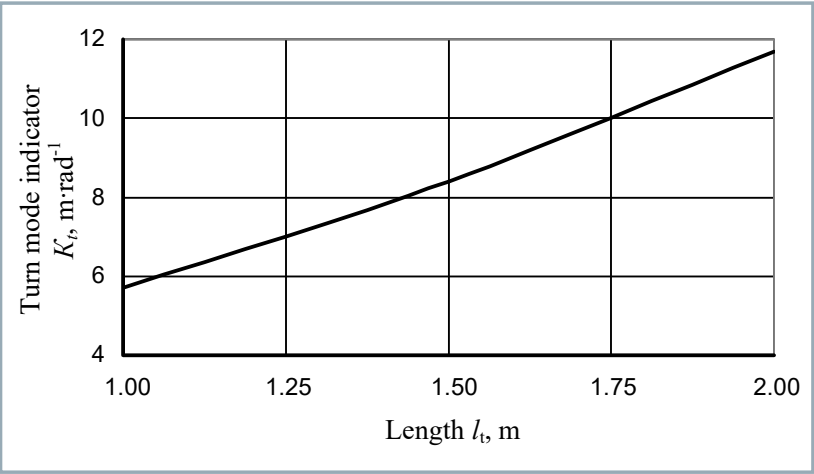

Fig. 5 Dependence of the indicator $K_{t}$ of the rotation mode machine-tractor unit on the distance $L_{t}$ between the coupling frame and the rear axle of the tractor

speed of not exceeding $2.5 \mathrm{~m} \cdot \mathrm{s}^{-1}$ and the average angular velocity of the steering wheels of the aggregating tractor $0.22 \mathrm{rad} \cdot \mathrm{s}^{-1}$.

At the same time, in regards to the left-hand manoeuvre, the rotation-ability of the observed aggregate is principally limited mainly due to the angle of rotation of its right seeding machine, as well as other factors. This is the reason why control action duration of the mechanism of aggregate rotation in the sections of variable curvature should be performed in a way fully utilizing this design rotation angle of the right seeding machine. The latter is particularly determined by the distance $L_{t}$ between the frame of the twomachine coupling and the axis of the rear tractor wheels. According to the results, Fig. 5 shows the dependence of the indicator $K_{t}$ of the enhanced machine-tractor unit turning mode on the indicated distance $L_{t}$.

From the presented graphical dependence, it is obvious that the optimum value of the indicator of the turning mode $K_{t}^{\text {opt }}$ can actually be achieved by increasing distance $L_{t}$ between the frame of the two-machine coupling and the axis of the rear tractor wheels from 1.0 to $1.96 \mathrm{~m}$.

Investigation of the experimental seeding machine and tractor unit has shown that there is no practical need to implement such a design solution as increasing the distance $L_{t}$ between the frame of a two-machine coupling and the rear axle of the aggregate. After all, in addition to complicating the design of the machine-tractor unit, this leads to an increase in the distance of its exit on headland, which is undesirable.

A more fundamental solution to the problem of making the turn of the observed machine and tractor unit in the optimal mode $K_{t}^{\text {opt }}$ is to equip it with a special automatic device that would change its speed $v$ on headland in accordance with the angular speed $\omega$ of the turning of steering wheel. An algorithm for implementation of such a process is shown in Fig. 6.

According to Fig. 6 , the automation process of the turning mode of the enhanced two-machine unit on headlands can be represented as follows: when the unit would start to turn on headland, the special speed sensor of its movement will estimate the value of $v$.

Simultaneously, this special sensor will estimate also the angular velocity $\omega$ of the steering wheels of the aggregate. Software will evaluate the ratio of the forward speed $v$ to the angular velocity $\omega$ and compare the obtained value with the optimum value $K_{t}^{\text {opt }}$. If the indicator of the turning mode of the unit is not equal to the optimal one, the speed of its movement automatically starts to increase until the optimal value of $K_{t}^{\text {opt }}$ is reached.

\section{Conclusions}

1. The results of investigation of the operational properties of an aggregate consisting of two seeding machines SZ-3.6, the tractor of 1.4 traction class, and a semimounted coupling hitch have confirmed that it has high operational and technological efficiency in comparison to both single-machine and similar two-machine aggregates in the trailer coupling.

2. In comparison with a single seeding machine and tractor aggregate, utilization of the aggregate consisting of two new seeding machines on the basis of a semimounted coupling hitch shows an increase in the specific time necessary for turning at headland by $5 \%$, but allowing for twice the working width, increasing of working performance 1.96 times and reduction of fuel consumption by $20 \%$.

3. In order to ensure that both seeding machines would turn in the optimal mode, it is advisable to equip the aggregate with a special automatic device that would change the speed of movement on headland in compliance with the angular speed of the tractor steering wheels according to the developed algorithm.

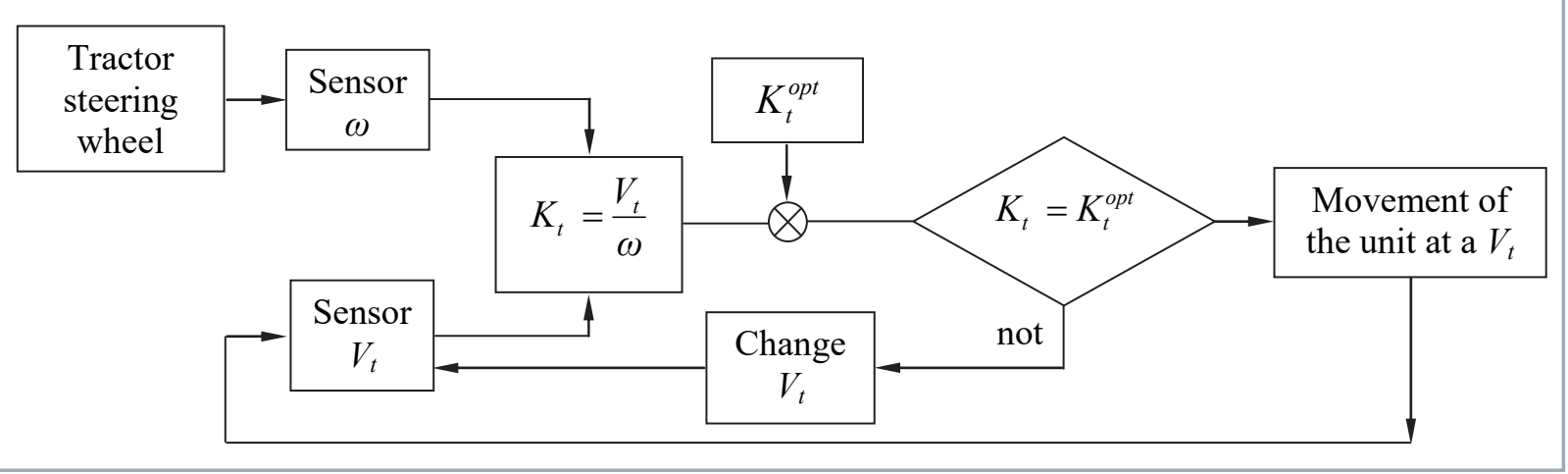

Fig. 6 Block diagram of automatic rotation mode algorithm of the aggregate of the two sowing machines and tractor 


\section{References}

ADLER, Ju. P. - MARKOVA, E. V. - GRANOVSKIJ, Ju. V. 1976. Planning of the experiment to determine the optimal conditions. Moscow: Nauka, 279 pp.

BELIJ, I. V. - VLASOV, K. P. - KLEPIKOV, V. B. 1989. Fundamentals of scientific research and technical creativity. Kharkov : Vysshaja shkola, Kharkov University printing house, $200 \mathrm{pp}$.

BULGAKOV, V. M. - KRAVCHUK, V. I. - NADYKTO, V. T. 2008. Aggregation of the ploughs. Kiev : Agrarnaja Nauka, 152 pp.

CVIKLOVIČ, V. - OLEJÁR, M. - HRUBÝ, D. - PALKOVÁ, Z. - LUKÁČ, O. HLAVÁČ, P. 2016. Navigation algorithm using fuzzy control method in mobile robotics. In Acta Technologica Agriculturae, vol. 19, no. 1, pp.19-23.

GOST 24055-88. 1988. Machinery testing. Methods of the operational and technological evaluation. Moscow, $15 \mathrm{pp}$.

IOFINOV, S. A. - BABENKO, E. P. - ZUEV, Ju. A. 1985. Handbook for the Operation of the Machine and Tractor Fleet. Moscow: Agropromizdat, $272 \mathrm{pp}$.

KRJUCHEV, V. N. - NADYKTO, V. T. - AJUBOV, A. M. - MASALABOV, V. N. 2009. Semimounted two-machines hitch. In Nauchnij Vestnik TDATU, vol. 9, no. 3, pp. 137-143.

KRJUCHEV, V.N. et al. 2013. Perspectives of the utilization of the combined machine-tractor aggregates. In Scientific News, vol. 21, no. 5, pp. 104-108.

KUŹNIAR, P. - SZPUNAR-KROK, E. - FINDURA, P. - BUCZEK, J. BOBRECKA-JAMRO, D. 2016. Physical and chemical properties of soybean seeds determine their susceptibility to mechanical damage. In Zemdirbyste-Agriculture, vol. 103, no. 2, pp. 183-192.
MACÁK, M. - ŽITŇÁK, M. - NOZDROVICKÝ, L. 2011. Using satellite navigation for seeding of wide-row and narrow-row crops. In Research in Agricultural Engineering, vol. 57, spec. issue, pp. S7-S13.

MASALABOV, V. N. 2012. Determination of the indicator of the turnability of the two-machines seeding aggregate. In Nauchnij Vestnik TDATU, vol. 2, no. 5, pp. 3-7.

NADYKTO, V. T. - MASALABOV, V. N. 2012. Research of the dynamic turnability of the two-machines aggregate. In Nauchnij Vestnik TDATU, vol. 2, no. 3, pp. 15-26.

TURAN, J. - VIŠACKI, V. - BURG, P. - FINDURA, P. - SEDLAR, A. D. RAJKOVIČ, M. B. - ZACH, M. 2017. Development of a soybean sowing model under laboratory conditions. In Acta Universitatis Agriculturae et Silviculturae Mendelianae Brunensis, vol. 65, no. 3, pp. 957-962.

TURAN, J. - VIŠACKI, V. - MEHANDŽIC, S. - FINDURA, P. - BURG, P. - SEDLÁR, A. 2014. Sowing quality indicators for a seed drill with overpressure. In Acta Universitatis Agriculturae et Silviculturae Mendelianae Brunensis, vol. 62, no. 6, pp. 1487-1492.

TURAN, J. - VIŠACKI, V. - SEDLAR, A. D. - PANTELIĆ, S. - FINDURA, P. - MÁCHAL, P. - MAREČEK, J. 2015. Seeder with different seeding apparatus in maize sowing. In Acta Universitatis Agriculturae et Silviculturae Mendelianae Brunensis, vol. 63, no. 1, pp. 137-141. 